\title{
Descrição dos métodos paleoartísticos para reconstruções de animais e vegetais fósseis
}

\author{
DESCRIPTION OF PALAEOARTISTIC METHOdS FOR RECONSTRUCTION OF FOSSILS OF ANIMALS AND PLANTS \\ Ariel Mllani Martine ${ }^{1}$, Fresia Ricardi-Branco ${ }^{2}$, Beatriz Beloto ${ }^{3}$ \\ 1- DGRN, I. Geociências, Unicamp, C. Postal 6152, CEP. 13083-970, Campinas, SP, Brasil. arielmmartine@yahoo.com.br \\ 2- DGRN, I. Geociências, Unicamp, C. Postal 6152, CEP. 13083-970, Campinas, SP, Brasil. fresia@ige.unicamp.br \\ 3- DGRN, Inst. Geociências, Unicamp, C. Postal 6152, CEP. 13083-970, Campinas, SP, Brasil. ariel_bia@yahoo.com.br
}

ABSTRACT: Since the second half of the $19^{\text {th }}$ century, paleontologists have been using drawings and paintings to reconstruct extinct organisms. These types of techniques are nowadays informally called paleoartistic reconstruction. The specimens reconstructed through scientific illustrations go beyond specialized literature to reach popular knowledge, having become an important tool for scientific dissemination. Due to the shortage of academic material about this subject in Brazil, the present work describes, through compared anatomy, the concepts and steps of the paleoartistic reconstruction processes, using three Brazilian fossil organisms as models - a dinosaur sauropoda (Aeolosaurus maximus), a bivalve mollusk (Itaimbea priscus), and a gymnosperm (Brachyphyllum obesum). The methodology applied to the reconstruction of these organisms can be applied to the reconstruction of any animal or plant fossil

Manuscrito:

Recebido: 25/02/2014

Corrigido: $16 / 03 / 2016$

Aceito: 21/03/2016

Citation: Martine A.M., Ricardi-Branco F. Beloto B. 2017. Descrição dos métodos paleoartísticos para reconstruções de animais e vegetais fósseis. Terræ Didatica, 13(2):101-112. < http:// www.ige.unicamp.br/terraedidatica/ $>$.

Keywords: Paleoart, Paleontological reconstruction

\section{Introdução}

Segundo Carvalho, 2000, a Paleontologia nunca foi tão popular, deixando de ser uma ciência restrita aos cientistas e às universidades. Pois é difícil encontrar quem não se interesse pela história da Terra e de seus habitantes durante o passado geológico.

Atualmente, admite-se que a popularidade da Paleontologia, fora do ambiente acadêmico, foi conquistada graças ao seu principal meio de divulgação: a reconstrução paleoartística. Paleoarte é um termo ainda informal constituído pela união das palavras paleontologia e arte e pode ser definida como representações artísticas que reconstroem cientificamente o aspecto em vida de organismos fósseis e/ou ambientes pretéritos. Nesta definição, a paleoarte não deve ser confundida com arte rupestre ou qualquer outro tipo de forma artística de povos ou sociedades primitivas. A paleoarte também não é a ilustração de fósseis a mão livre ou sob câmara clara ou ainda cartografia. A paleoarte visa reconstruir o organismo extinto em vida; não é uma cópia de seu material fóssil. Executadas por meio de desenhos, pinturas ou esculturas, as reconstruções representam o mais eficiente elo entre a pesquisa paleontológica e o público em geral, sendo assim, uma importante ferramenta de divulgação científica.
Uma imagem possui um alcance muito maior do que qualquer texto. A simples contemplação de uma dessas imagens pode representar o primeiro passo rumo ao interesse científico. Para leigos em anatomia, a figura de um esqueleto é algo muito abstrato. Mais abstrata ainda é a figura de um fóssil, que é na maioria das vezes uma pequena parcela de um esqueleto e, geralmente, disforme. Assim, o fóssil é algo quase ilegível para o não-especialista, e jamais o público leigo que, por meio unicamente de um fóssil, ou de uma descrição científica, poderia imaginar o formato do animal dono daqueles vestígios. Quando reconstruído graças a técnicas paleoartísticas, o mesmo organismo, "um estranho pedaço de rocha", passa a ser inteligível e ficar mais atraente e o grande público passa a entender o que realmente ele representa.

Esta ligação entre o objeto e o público é muito importante, pois o interesse popular alavanca as pesquisas paleontológicas, facilita a captação de recursos e garante um maior espaço reservado às geociências em publicações e exposições museais.

As primeiras reconstruções paleoartísticas foram produzidas por Charles Laurillard perante as orientações de Geoge Cuvier [1769-1832] em 1822. As ilustrações exibem a reconstrução em vida de quatro espécies de mamíferos do período Paleó- 
geno da França e fazem parte da segunda edição de Investigações sobre ossadas fósseis de autoria de Cuvier (Fig. 1). Desde então, reconstruções passaram a acompanhar a maioria das descrições e textos sobre paleontologia. No século XX, com o advento das grandes exposições museais e substancial aumento editorial, as reconstruções tornaram-se ainda mais frequentes, exigindo artistas com conhecimento em História Natural que, então, passaram a trabalhar exclusivamente com reconstruções. Dentre muitos se destacam os norte-americanos Charles Knight [1874-1953] e Rudolph Franz Zallinger [19191995] e o tcheco Zdenek Burian [1905-1981]. As imagens criadas por essa geração de artistas transcenderam a divulgação científica e, até o final da década de 1970, a ideia de organismos extintos em vida vinham diretamente destas imagens, que influenciaram toda a cultura exposta a elas. Como exemplo pode-se observar as produções cinematográficas com temas pré-históricos produzidos entre 1930 e 1980, cujos cenários são claras reproduções das pinturas de Knight, Zallinger ou Burian.

Atualmente, a paleoarte é amplamente utilizada e adota conhecimentos que vão além da Paleontologia, como Ecologia, Sedimentologia, Anatomia comparada, Etologia e Evolução. As reconstruções geralmente são executadas por meio da parceria entre paleontólogo e ilustrador/escultor científico e além do aspecto em vida busca-se também determinar possíveis relações comportamentais e ecológicas graças a interpretações tafonômicas. Imagens obtidas em tomógrafos de alta resolução e sofisticados softwares são também empregados para auxiliar na reconstrução de músculos e órgãos que preenchiam cavidades e elaboração da biomecânica (Anderson et al. 2012).

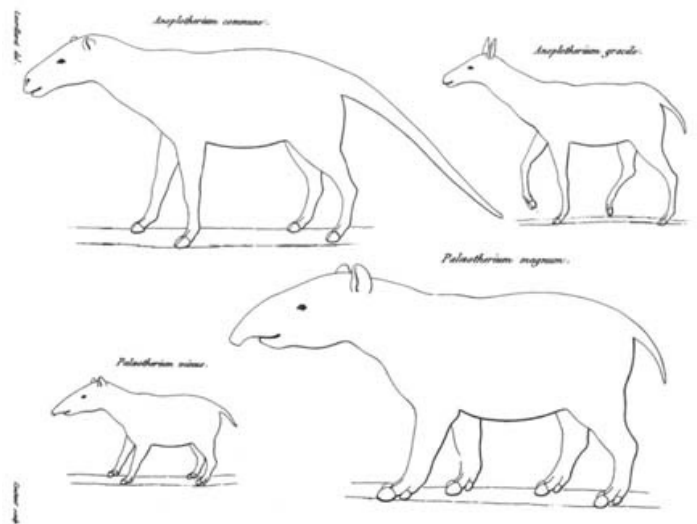

Figura 1. Reconstrução de mamíferos fósseis da França elaborados por George Cuvier e ilustrados por Charles Laurillard em 1822. Fonte: Rudwick (1992)
Diferente das primeiras reconstruções, no momento presente, por mérito do amadurecimento e multidisciplinaridade das pesquisas paleontológicas, as reconstruções paleoartísticas são menos especulativas e, quando corretamente executadas, podem representar imagens e cenários fiéis do passado geológico.

Uma reconstrução pode ser tanto individual (quando reconstrói uma espécie fóssil isolada), quanto paleoambiental (quando recria um antigo ambiente, mesmo que em parte, com suas feições geológicas e biota fóssil). Neste artigo são expostas as metodologias necessárias a reconstruções individuais.

\section{Objetivos}

O artigo tem o objetivo de descrever conceitos e etapas dos processos de reconstrução paleoartística, estabelecendo metodologias e critérios de reconstruções individuais que podem ser aplicados a qualquer organismo, animal ou vegetal para a disseminação de informações de descobertas paleontológicas.

\section{Materiais e métodos}

Para demonstrar as várias possibilidades de reconstruções, neste trabalho foram elaboradas ilustrações com diferentes materiais e técnicas artísticas. Como modelo, são utilizadas três espécies fósseis brasileiros: Aeolosaurus maximus Santucci \& Arruda-Campos 2011, Itaimbea priscus Ihering 1913 e Brachyphyllum obesum Heer 1881, que representam respectivamente um vertebrado, um invertebrado e um vegetal.

Classificação das técnicas utilizadas:

- Técnica 1- Lápis HB e 6B em papel sulfite A4.

- Técnica 2 - Tinta nanquim preta e branca e caneta nanquim preta descartável $\mathrm{n}^{\circ} 0.05, \mathrm{n}^{\circ}$ $0.1 \mathrm{e} \mathrm{n}^{\circ} 0.5$ em cartolina ou sulfite.

- Técnica 3 - Aguada de tinta acrílica e lápis de cor aquarelável em papel tipo canson A4.

- Técnica 4 - Tinta acrílica em tela

- Técnica 5 - Ilustração digital.

- Técnica 6 - Tinta acrílica em papel tipo canson A4.

A classificação é indicada na legenda de cada ilustração, possibilitando a identificação da técnica artística utilizada. 
Eventualmente, a técnica 1 (Lápis HB e 6B em papel) pode servir como primeira etapa nas reconstruções, pois é adequada para realização de esboços.

\section{Reconstrução individual}

Em uma reconstrução individual, o organismo fóssil deve apresentar, como resultado final, o aspecto que esta espécie teria em vida, de forma mais correta e natural possível. Para isso, o trabalho de reconstrução deve ser executado usando todas as informações e proporções anatômicas presentes no fóssil estudado. Tais reconstruções são elaboradas em etapas com critérios que variam de acordo com o grupo taxonômico.

\section{Reconstrução de vertebrados}

Os vertebrados são os organismos fósseis mais comumente reconstituídos.

A reconstrução individual de espécies deste grupo pode ser dividida em ao menos quatro etapas: reconstrução esquelética, reconstrução muscular, reconstrução tegumentar e reconstrução de cor e padronagem.

A reestruturação do esqueleto é a etapa inicial do processo de reconstrução de um vertebrado. Mesmo fósseis completos e bem preservados devem ser redesenhados, pois tais fósseis, na melhor das hipóteses, apresentam o esqueleto articulado em posição de morte. Porém, na grande maioria das vezes, estes esqueletos são encontrados desarticulados, fragmentados, incompletos e deformados pelo processo de fossilização.

O primeiro estágio da reconstrução do esqueleto é a definição de uma pose, uma postura adotada pelo animal em vida. Para execução deste estágio, deve-se observar detalhadamente o fóssil. Um estudo dos ossos permite definir, mesmo que superficialmente, os limites de extensão das articulações. Este estudo é muito importante, pois além de definir quais os movimentos o animal poderia, ou não fazer, também estabelece em qual posição a articulação estaria mais confortável, ou seja, a posição em que o animal passaria a maior parte do tempo. Esta é a pose que deve ser adotada. Formas atuais morfologicamente semelhantes, ou filogeneticamente próximas ao fóssil, podem também ser usadas como modelos para pose. Estes estudos podem refinar a postura do esqueleto, deixando-o com um aspecto mais natural.

Após a escolha da pose, o esqueleto deve ser desenhado, preferencialmente de perfil, sem fragmentações ou deformidades provenientes da fos- silização, corretamente articulado e apresentado de forma clara, com as principais estruturas aparentes. Fósseis incompletos devem ter suas partes faltantes integradas por meio da anatomia comparada, ou seja, partes faltantes do esqueleto são reconstruídas usando como referência ossos de outra espécie com maior proximidade filogenética. Estes ossos são adaptados às proporções do novo esqueleto, concluindo, assim, a reconstrução osteológica.

A segunda etapa para reconstrução de um vertebrado é o desenho de sua musculatura. Os ossos contêm marcas, sulcos e cristas que indicam onde eram inseridos músculos e tendões. Nesta etapa de reconstrução deve-se priorizar o restauro dos principais e maiores músculos externos, pois são estes que conferem volume ao animal.

A etapa seguinte consiste em ilustrar o possível aspecto tegumentar do animal. Em raras espécies a impressão tegumentar pode ser observada nos fósseis, porém a maioria não apresenta este tipo de preservação. Nestes casos, a reconstrução tegumentar deve se basear novamente em anatomia comparada, buscando em animais atuais ou fósseis, com maior proximidade filogenética com a espécie a ser reconstruída, referencias como formato e padrão de escamas ou textura da pele.

A última etapa da reconstrução de um organismo fóssil é aplicação de cores e possíveis padrões de manchas.

O primeiro fóssil de vertebrado estudado com estruturas preservadas que remetem seguramente a cor é Anchiornis huxleyi Xu et al. 2009, um pequeno terópode emplumado do Jurássico superior da China. O fóssil apresenta penas com manchas, que quando observadas ao microscópio, revelam grânulos de pigmentos, os melanossomos. Os grânulos estudados apresentavam ao menos dois formatos diferentes: um ovalóide e outro mais comprido, em forma de bastão. Estudos revelaram que os melanossomos ovalóides eram responsáveis pelos pigmentos pretos, enquanto, os melanossomos alongados conferiam uma cor que variava do vermelho ao marrom. As regiões do corpo onde essas estruturas estão ausentes foram interpretadas como sendo de cor branca. Assim, a decodificação dos melanossomos permitiu a mais segura reconstrução de cor de um vertebrado fóssil. Em vida, $A$. huxleyi possuía crista cor de ferrugem, corpo acinzentado e asas com faixas pretas e brancas.

Aplicada recentemente a outras espécies, a decodificação de melanossomos é um estudo novo e só pode ser desenvolvido em pouquíssimos fósseis raramente bem preservados. Desta forma é impossível 
estabelecer a cor exata da quase totalidade dos organismos fósseis, e as reconstruções de cor assumem uma certa "licença artística".

Entretanto, mesmo sendo uma ação especulativa, a aplicação de cor em uma reconstrução deve ser executada com ponderação. Apesar de não sabermos a verdadeira cor da grande maioria dos vertebrados fosseis, podemos recriar uma coloração possível comparando a espécie fóssil e seu paleoambiente com formas atuais semelhantes, que vivem em ambientes ou ocupem um nicho ecológico equivalente ao do fóssil estudado.

A comparação taxonômica, morfológica, ambiental e até etológica é base para aplicação de cor em animais extintos.

\section{Reconstrução de invertebrados}

A reconstrução do aspecto em vida de invertebrados consiste em uma tarefa mais simples que a de um vertebrado, uma vez que os fósseis de invertebrados, em sua maioria, possuem impressões de conchas, carapaças e exoesqueletos. Todas estas estruturas definem o formato do organismo com precisão; isso significa que, diferentemente de vertebrados, que exigem uma reconstrução muscular e tegumentar para definição de seu formato em vida, em invertebrados o formato impresso nos fósseis representa, frequentemente, o idêntico formato que o animal teria em vida. Mesmo invertebrados de corpo mole, quando preservados, apresentam ao menos a silhueta do corpo, permitindo um imediato reconhecimento do formato que este animal teve quando vivo.

Uma reconstrução de invertebrado torna-se mais difícil quando o animal a ser reconstruído foi descrito apenas por um fragmento do corpo, como uma asa ou uma perna isolada. Nestes casos, assim como em vertebrados, usam-se como referência, para completar o animal, estruturas anatômicas de outras espécies mais completas que possuem proximidade filogenética com o animal a ser reconstruído.

Uma vez que, na maioria das vezes, as características externas dos invertebrados já estão presentes nos fósseis, o trabalho de reconstrução, nestes casos, ilustrar o animal em uma posição que ele comumente assumiria em vida e aplicar-lhe cor.

\section{Reconstrução de Vegetais Fósseis}

Assim como em invertebrados com exoesqueletos, a reconstrução de partes de vegetais fossilizados é tarefa relativamente simples, pois todos os dados morfológicos necessários à reconstrução estão claramente presentes no próprio fóssil. Em uma folha fossilizada, por exemplo, pode-se observar o desenho de suas margens e muitas vezes até sua complexa rede de nervuras. O formato que a folha revela impressa no fóssil é o mesmo que ela tinha antes de ser fossilizada. Neste caso, o trabalho de reconstrução pode ser resumido em copiar o desenho do fóssil aplicando-lhe volume e cor.

O desafio na reconstrução de plantas fósseis está em reconstruí-las em sua totalidade. Mesmo fósseis bem preservados contêm apenas partes isoladas, como folhas, ramos, inflorescências, troncos ou raízes. São raríssimos os fósseis que apresentam uma planta preservada completa. Em vegetais de maior porte, fósseis assim são ainda mais raros.

Talvez devido à dificuldade de se elaborar uma reconstrução precisa, ou por um maior interesse popular em paleozoologia, as reconstruções paleobotânicas são menos comuns e muitas vezes aparecem de forma estilizada como elementos secundários na composição de cenas que mostram anfíbios e insetos do período Carbonífero ou dinossauros da Era Mesozoica.

Trabalhos recentes têm apresentado interessantes modelos de reconstruções, alguns expondo até mesmo equações para determinar a altura ou a largura de uma árvore extinta a partir de um fragmento de um tronco, determinando, assim, sua possível silhueta (Philipp 2009). Entretanto, uma forma geral, o processo de reconstrução de vegetais fósseis segue os mesmos princípios usados para reconstrução de animais: a anatomia comparada.

\section{Resultados}

\section{Reconstrução de Aelosaurus maximus como modelo de reconstrução de vertebrado}

Os dinossauros saurópodes foram os maiores animais que já caminharam sobre a Terra.

Ao longo de sua evolução, muitas espécies surgiram, algumas de formas bizarras, mas de um modo geral as características morfológicas principais dos saurópodes sempre se mantiveram. Dentre estas características as mais relevantes são: corpo robusto e volumoso, sustentado por patas colunares em uma posição quadrúpede, cauda e pescoço compridos com cabeça proporcionalmente pequena, com dentes frágeis, adaptados a uma alimentação exclusivamente herbívora. 
A família Titanosauridae foi a última família de saurópodes a surgir, com espécies que viveram até o final do período Cretáceo. De ampla distribuição geográfica, os Titanosauridae são os saurópodes mais comuns no Brasil.

Aelosaurus é um gênero de Titanosauridae com duas espécies argentinas e uma brasileira: Aelosaurus maximus. Em vida, $A$. maximus poderia chegar até $20 \mathrm{~m}$ de comprimento, sendo assim, um dos maiores dinossauros do Brasil. Seus fósseis foram encontrados no município de Monte Alto, São Paulo, em sedimentos pertencentes à Formação Adamantina (Turoniano/Santoniano) da Bacia Bauru (Santucci \& Arruda-Campos 2011).

Pegadas fósseis de saurópodes encontradas em várias partes do mundo sugerem que estes animais possuíam hábito gregário, como os atuais elefantes africanos (Bakker 1988). Assim também deveria viver $A$. maximus, em grandes manadas que cruzavam a planície semiárida em busca de água e alimento.

\section{Reconstrução esquelética}

A. maximus foi descrito a partir de um esqueleto incompleto (Fig. 2). A reconstrução esquelética é possível usando dados osteológicos obtidos a partir de outras espécies com proximidade filogenética, como Aeolosaurus rionegrinus Powell 1987 e Gondwanatitan faustoi Kellner \& Azevedo 1999. Estes dados são utilizados como referência para elaboração de cada osso faltante, que será adaptado e enxertado ao esqueleto de $A$. maximus, completando deste modo, suas lacunas. Em $A$. maximus este método oferece uma reconstrução muito confiável, uma vez que a anatomia de Titanosauridae é relativamente conservadora (Novas 2009).

De um modo geral, o esqueleto dos saurópodes estava totalmente adaptado ao gigantismo, permitindo que o animal se locomovesse sem desperdício de energia (Norman 1996). O crânio é pequeno e frágil, se comparado ao corpo. As órbitas possuem formato de gota invertida e nelas se alojam o anel esclerótico, um envoltório ósseo que margeia e define o tamanho dos olhos. As narinas externas estão alojadas na parte superior do crânio, quase que entre os olhos. Os dentes são pequenos e cilíndricos, sutilmente curvados para trás e com a ponta chanfrada em forma de "V" (Paul 2000).

O esqueleto axial é moderadamente articulado. Não há uma fórmula vertebral precisa, mas em

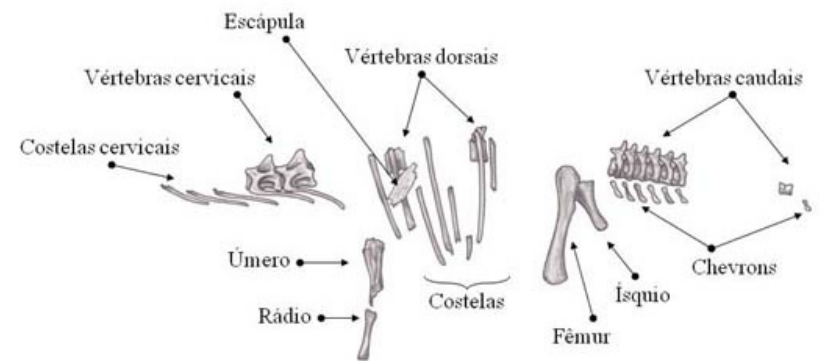

Figura 2. Representação artística de Fósseis de Aelosaurus maximus. Ilustração de Ariel Milani Martine

média, Titanosauridae possuem uma sequência vertebral constituída por treze vértebras cervicais, 10 a 12 dorsais, seis sacrais e algo em torno de 30 a 40 caudais (Novas 2009). As vértebras são pneumáticas, com zonas cavadas (pleurocelos) e ricas em cristas de suporte, o que permite uma considerável redução de peso sem perda de resistência (Wedel 2005). As vértebras cervicais são dotadas de finas e longas costelas cervicais, que se posicionam horizontalmente e são voltadas para trás, articulando-se moderadamente de forma imbricada com a posterior. O comprimento das costelas cervicais pode variar de uma vez e meia a um dobro do tamanho da vértebra da qual faz parte. As patas articulam-se de forma mais ou menos reta, como colunas, ideais para suportar o grande peso. O fêmur é longo e reto, pois curvas em seu formato tenderiam a debilitá-lo (Norman 1996). Nos pés, os metatarsos e falanges assumem uma disposição muito semelhante à dos elefantes. Em relação a outros saurópodes, Titanosauridae possuem um distanciamento maior entre as patas direitas e esquerdas, com ossos mais robustos e volumosos, e patas dianteiras desprovidas de falanges (Fig. 3).

A cintura pélvica é larga e volumosa, composta por ílio, púbis e ísquio, e suportam os fortes músculos das pernas e cauda (Norman 1996).

\section{Reconstrução muscular}

Muitas reconstruções de saurópodes foram efetuadas usando como base a musculatura de grandes mamíferos. Este é um erro muito comum. Para reconstruir $A$. maximus de forma correta deve-se usar como referência a musculatura de aves e crocodilianos, os representantes vivos mais próximos filogeneticamente dos saurópodes. Estes músculos devem ser adaptados aos ossos de $A$. maximus usando como guia as marcas de fixação e inserção muscular deixados em seus ossos. Estas marcas propiciam recompor o volume destes músculos, permitindo uma reconstrução relativamente segura da silhueta do animal (Fig. 4). 
Assim como em répteis e aves atuais, o crânio dos saurópodes era pobremente coberto por músculos faciais (Paul 2000). Os músculos mais evidentes do crânio eram os responsáveis pela movimentação da mandíbula, pálpebras e narinas. Os músculos nasais, junto a cartilagens, prolongavam as narinas externas, na parte superior do crânio, próximo as órbitas até pouco mais da metade do comprimento do crânio. O restante do crânio é coberto por pele que se fixava diretamente aos ossos. Os músculos do pescoço eram alongados e mantinham-no em posição mais ou menos horizontal. Inseridos nos espinhos neurais das vértebras cervicais, o músculo Espinalis capitis, percorria a parte dorsal do pescoço até a base do crânio e, quando contraído, erguia a cabeça do animal. O músculo Longissimus cervis era posicionado lateralmente e estava conectado às vértebras de cada lado do pescoço, sendo responsável pelo seu movimento lateral. $\mathrm{Na}$ base do pescoço estava localizado o músculo Levator escapulae, que puxava a escápula anteriormente.

No corpo, os músculos mais sobressalentes eram o Trapezius, que puxava a escápula dorsal e anteriormente, o músculo Latissimus dorsi que auxiliava a trazer o braço junto ao corpo, o músculo Serratus que puxava a escápula ventral e posteriormente, e auxiliava o suporte da parte anterior do corpo e o músculo Obliquo esterno, que sustentava a parede do abdômen e auxiliava a flexionar o corpo lateralmente (Chiasson 1962).

Nos membros anteriores destacavam-se o músculo Deltoide escapularis que puxava o úmero anteriormente, e o músculo Teres, que agia de forma antagônica. Da mesma forma, o músculo Biceps puxava o antebraço, flexionando-o, enquanto, o músculo Triceps, opondo-se ao anterior, puxava a região do cotovelo, estendendo desta forma o antebraço (Chiasson 1962).

O mais visível músculo dos membros posteriores era o Quadríceps, conhecido também como Iliotibialis. Este grande músculo, que delimitava a maior parte do formato da coxa, quando contraído, estendia a perna, deixando-a em uma típica posição colunar. Contrário a este movimento, o músculo Iliofibulares, quando contraído flexionava as pernas. Outros músculos importantes das pernas são o Gastrocnemius, que estendiam os pés e o extensor Digitorium longus, que estendiam os dígitos (Chiasson 1962).

Os fortes músculos da cauda mantinham-na sempre suspensa, de forma que enquanto os saurópodes caminhavam, a cauda nunca se arrastava pelo

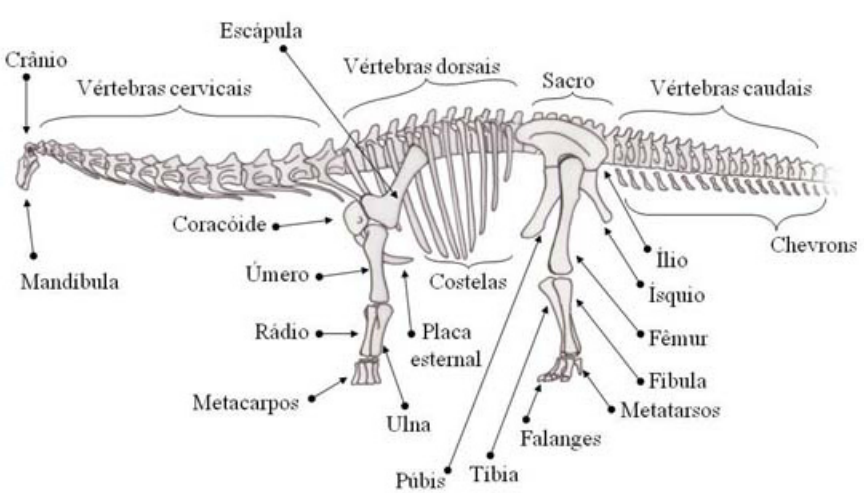

Figura 3. Reconstrução esquelética de Aelosaurus maximus. Ilustração de Ariel Milani Martine (Técnica 2)

chão, como ilustrado em reconstruções feitas até a década de 1980 (Bakker 1988) Dentre os músculos da cauda, o mais evidente era o Caudofemoralis longus, responsável pelo movimento lateral da cauda.

\section{Reconstrução tegumentar}

Partes moles, como tegumento, raramente são fossilizados, e em alguns grupos de dinossauros o revestimento cutâneo ainda é desconhecido. Mesmo raro, as poucas amostras de pele fossilizada de saurópodes fornecem informações suficientes para uma reconstrução relativamente segura. Os fósseis revelam que o tegumento dos saurópodes era formado por uma grossa malha de escamas, com formato que variava do circular ao hexagonal, dispostas uma ao lado da outra, formando um grande mosaico de escamas de tamanhos variados (Upchrch et al. 2004). As escamas maiores ficavam em áreas do corpo com menor mobilidade, enquanto áreas mais flexíveis eram revestidas por escamas menores. Mesmo queratinizadas, as bordas das escamas eram menos rígidas permitindo uma livre articulação com as escamas vizinhas, como

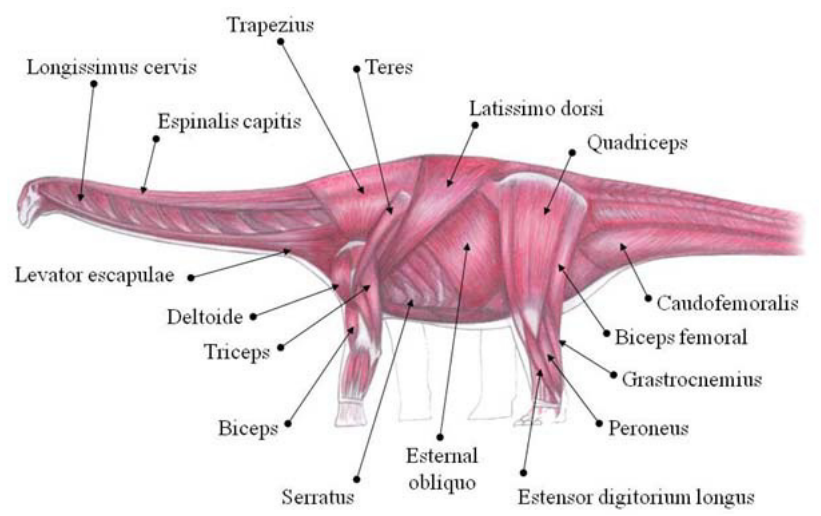

Figura 4. Reconstrução muscular de Aelosaurus maximus. Ilustração de Ariel Milani Martine (Técnica 3) 
acontece em crocodilianos atuais. O corpo de $A$. maximus deveria ser quase totalmente coberto por esta malha, e em pontos de constante movimentação, poderiam ocorrer também rugas e pregas de pele, dando-lhe um aspecto, em parte, semelhante aos atuais paquidermes.

Alguns titanosaurideos possuíam o dorso coberto por placas ósseas denominadas osteodermos. Com tamanhos diferentes, essas placas eram dispostas de forma mais ou menos aleatória e juntas constituíam uma eficiente couraça protetora. No município de Ibirá, São Paulo, foi encontrado um grande osteodermo isolado, que poderia ser atribuído a um $A$. maximus (Marinho \& Iori 2011). Assim, o dorso de A. maximus poderia ser coberto com osteodermos, da mesma forma que o Titanosauridae argentino Saltasaurus loricatus Bonaparte \& Powell 1980.

\section{Reconstrução de cor}

Dos fósseis encontrados atribuídos a saurópodes, nenhum apresenta qualquer indício que possa revelar a cor desses animais em vida e animais atuais mais próximos filogeneticamente a este grupo ocupam nichos ecológicos totalmente diferente, não podendo ser usados como referência de cor. Assim, a reconstrução da cor de $A$. maximus pode ser estimada usando como referência animais atuais, sem relações filogenéticas, que ocupem um nicho ecológico semelhante ao ocupado por $A$. maximus.

$A$. maximus foi um grande herbívoro, e provavelmente vivia em manadas em um ambiente semiárido. Atualmente um grande mamífero compartilha as mesmas características: o elefante africano (Loxodonta africanus Gray 1821). Essa espécie de elefante é o maior animal nas savanas africanas, e quando adulto raramente é abatido por inimigos naturais, não precisando assim, de um padrão de camuflagem que o oculte de predadores. Como o tamanho representa a estratégia de proteção, o elefante africano possui uma única cor em todo o corpo: o cinza escuro. Mas devido aos constantes banhos de lama e a poeira do semiárido, que impregna sua pele, na maior parte do tempo, o elefante africano apresenta uma coloração que varia do ocre ao marrom avermelhado. Dessa forma, graças às similaridades físicas, ecológicas e possivelmente comportamentais é bem provável que a coloração de $A$. maximus fosse semelhante à de um elefante africano (Fig. 5).

Em muitas espécies atuais o padrão de cor e manchas de indivíduos juvenis são diferentes da

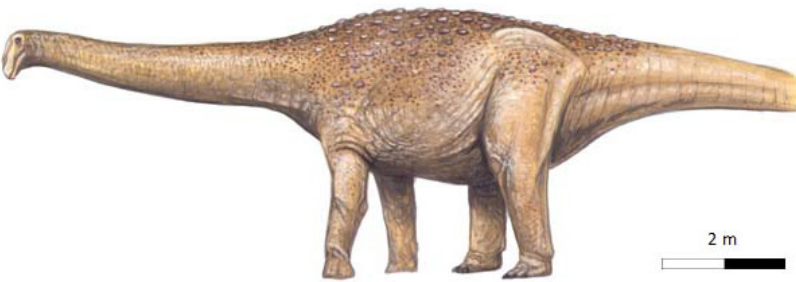

Figura 5. Reconstrução em vida de Aelosaurus maximus. llustração de Ariel Milani Martine (Técnica 6)

coloração de indivíduos adultos. A explicação para esta característica ontogênica se encontra no fato de indivíduos jovens estarem mais vulneráveis ao ataque de predadores, por isso, possuem um padrão de cor que melhor os mimetizam em seu meio ambiente. A medida em que vão crescendo, diminuem o número de inimigos naturais e gradativamente a coloração muda pra o padrão definitivo adulto. Em muitas espécies fósseis esta mudança de coloração pode ter ocorrido. Entretanto, comparando com a ecologia de animais atuais, é pouco provável que a coloração de $A$. maximus mudasse significativamente ao longo da vida. Animais atuais que vivem em manadas, quando jovens, são protegidos pelo grupo não havendo, assim, a necessidade de uma coloração de camuflagem diferente da do adulto (Fig. 6).

A grande maioria dos saurópodes, assim como A. maximus, deveria ter coloração semelhante à dos elefantes. Porém, usar unicamente a cor de grandes mamíferos como referência para ilustrar qualquer dinossauro não é correto. Grandes mamíferos são monocromáticos e opacos, não só por condicionamento ao ambiente, mas também, por sua baixa percepção de cores. Por isso, nada adiantaria estes animais ostentarem em seus corpos cores variadas e vivas para demarcação de território ou atração sexual. Dinossauros, assim como seus descendentes, as aves,

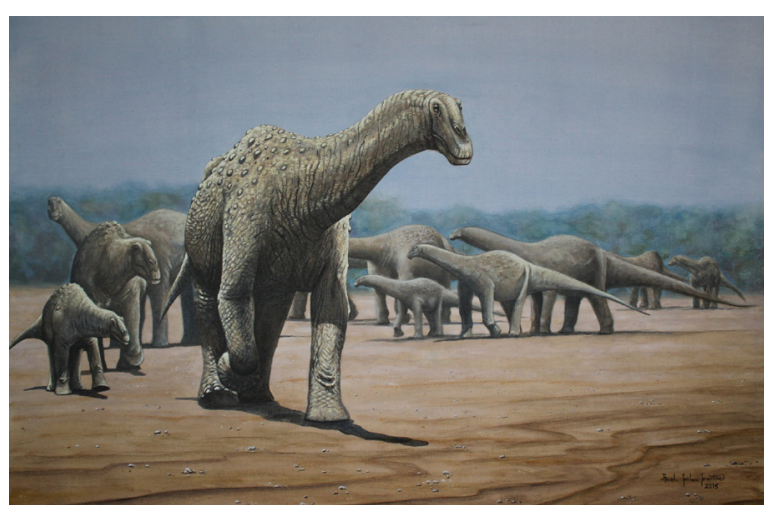

Figura 6. Reconstrução de uma manada de Aelosaurus maximus com indivíduos de idades variadas. Pintura de Ariel Milani Martine (Técnica 4) 
provavelmente enxergavam bem e colorido. Então, é mais seguro afirmar que muitas espécies de dinossauros, sobretudo os de pequeno e médio porte, ou que apresentavam algum tipo de adorno poderiam ter um colorido intenso e variado (Paul 2000).

\section{Reconstrução de Itaimbea priscus como modelo de reconstrução de invertebrado}

Itaimbea priscus foi um bivalve da família Iridinidae com concha oval, subcomprimida, borda anterior arredondada e borda dorsal reta e inclinada para baixo. Este molusco foi encontrado em sedimentos arenosos pertencentes a Formação Adamantina, Cretáceo Superior (Turoniano/Santoniano) da Bacia Bauru, no município de São José dos Dourados, São Paulo. A extremidade posterior da concha foi quebrada e o holótipo encontra-se desaparecido. Desta forma a reconstrução será executada a partir da figura pertencente ao trabalho de Mezzalira, publicado em 1974 (Fig. 7).

O passo inicial para reconstrução de $I$. priscus consiste em reconstituir a borda da concha. Seguindo o contorno das bordas preservadas e as linhas de crescimento observadas na figura pode-se estimar a silhueta da concha. O resultado desta reconstrução, já efetuada no trabalho de Mezzalira (1974), pode ser refinado em uma ilustração que a apresente integralmente reconstruída (Fig. 8).

Para estabelecer a cor da concha de I. priscus, deve-se usar como referência as cores de bivalves atuas de água doce. Diferente de bivalves marinhos, que apresentam uma grande variedade de desenhos e cores em suas conchas, os bivalves de água doce são em sua maioria monocromáticos, e apresentam tonalidades sempre próximas ao marrom escuro. A cor de I. priscus deveria estar dentro desta margem de tons (Fig. 9).

\section{Reconstrução de Brachyphylum obesum como modelo de reconstrução de vegetal}

B. obesum foi uma conífera da família Cheirolepidiaceae, comuns durante a Era Mesozóica e hoje extinta. Essa família teve uma ampla distribuição geográfica, sendo particularmente abundante em camadas pertencentes ao EoCretáceo. A espécie foi descrita a partir de fósseis encontrados em Portugal (Lima et al. 2012). Na Bacia do Araripe, fósseis de $B$. obesum foram registrados inicialmente no Membro Romualdo (Duarte1985) e posteriormente no Mem- bro Crato (Albiano/Aptiano) (Kunsmann, Mohr \& Bernardes-de-Oliveira 2004), onde revelam um melhor estado de preservação (Fig. 10). Todo material seguramente atribuído a $B$. obesum é constituído unicamente por ramos. Estes fósseis apresentam numerosas ramificações alternadas, curtas e espessas, com região distal obtusa. Suas folhas são rômbicas e densamente imbricadas de aparência coriácea e o dorso levemente estriado. Folhas com a cutícula preservadas apresentam estômatos submersos e os formatos suculentos dos ramos e folhas sugerem uma adaptação a ambientes com climas semi-áridos ou com um déficit hídrico pronunciado.

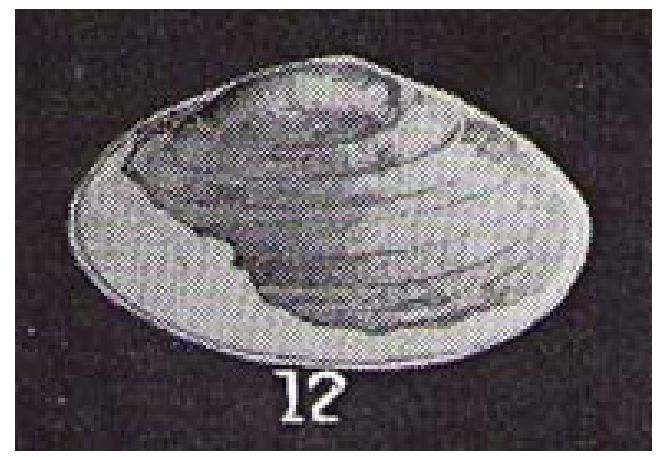

Figura 7. Itaimbea priscus. Fonte: Mezzalira 1974

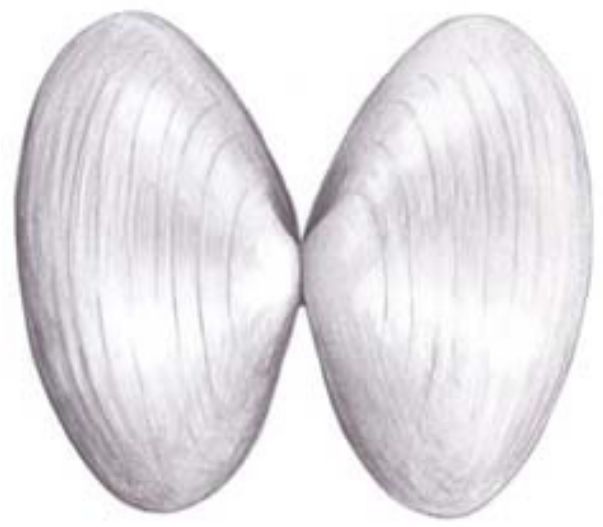

Figura 8. Reconstrução da concha de Itaimbea priscus. Ilustração de Ariel Milani Martine (Técnica 1)

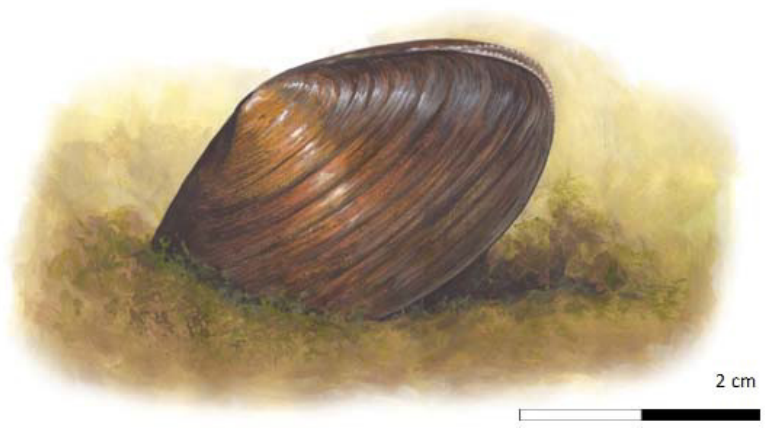

Figura 9. Reconstrução em vida de Itaimbea priscus. Ilustração de Ariel Milani Martine (Técnica 6). 


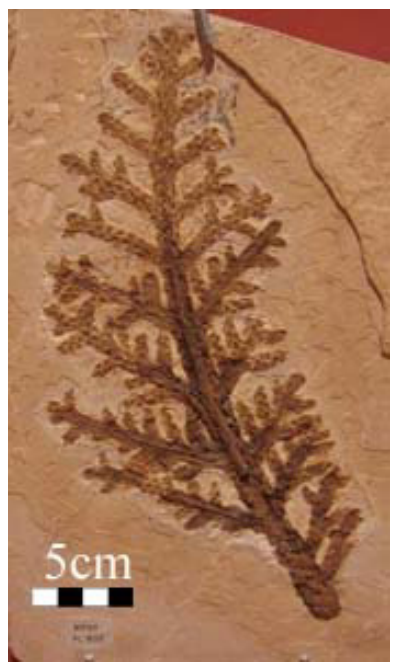

Figura 10. Reconstituição em vida de Itaimbea priscus. llustração de Ariel Milani Martine (Técnica 6).

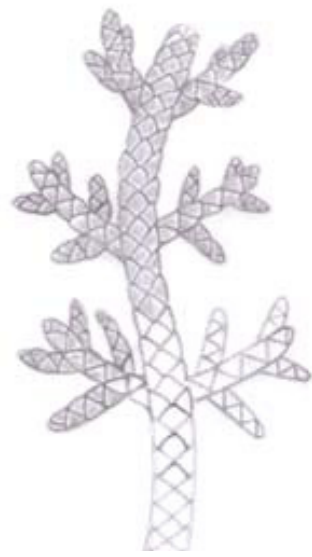

Figura 11. Esboço inicial de ramo de Brachyphylum obesum, mostrando os traçados principais. Ilustração de Ariel Milani Martine (Técnica 1)

O trabalho de reconstrução de um vegetal fóssil é dividido em duas etapas: a primeira visa reconstruir apenas a parte da planta preservada no fóssil. A segunda consiste em reconstruir o aspecto da planta em vida, na sua totalidade, com ou sem as raízes. A reconstrução dos ramos representa a primeira etapa do processo de reconstrução.

\section{Reconstrução dos ramos de Brachyphylum obesum}

O trabalho de reconstrução vegetal inicia-se através de um esboço composto basicamente por linhas que ilustram o formato e as principais características da morfologia externa da espécie. Este esboço preliminar pode ser efetuado a partir de fotografias ou preferencialmente a partir de fósseis originais. O esboço tem a função de tornar mais claras as características morfológicas, que por vezes, são confusas no fóssil, além de gerar uma familiarização do ilustrador com essas estruturas, possibilitando uma maior facilidade em representá-las em desenhos mais elaborados executados posteriormente (Fig. 11).

O passo seguinte da reconstrução dos ramos de $B$. obesum é efetuado a partir da observação de vários fósseis desta espécie, buscando uma padronizar a disposição dos ramos. B. obesum possui ramos alternados que podem chegar a quatro subdivisões. Em relação ao eixo central, os ramos laterais estão dispostos em ângulos que podem variar de $45^{\circ}$ a $75^{\circ}$. Este padrão de disposição associado aos detalhes ilustrados no esboço inicial são os mais importantes elementos para reconstrução (Fig. 12).

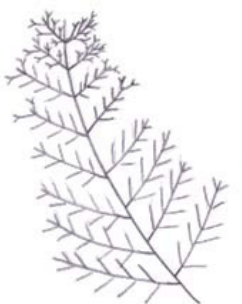

A B

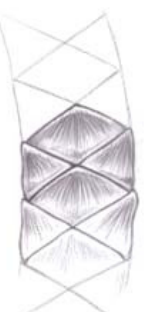

Figura 12. Desenho esquemático mostrando a disposição dos ramos (A) e detalhe das folhas (B) de Brachyphylum obesum. Ilustração de Ariel Milani Martine (Técnica 1)

Entretanto, antes de concluir uma reconstrução, deve-se considerar que por melhor que estejam preservados, a maioria dos fósseis contém a impressão de plantas em uma posição geralmente plana, onde todas as folhas e ramos encontram-se no mesmo nível. Este fato ocorre devido à natureza delicada das folhas, flores e ramos. Uma vez depositada entre os sedimentos estes ramos, com a diagênese, são comprimidos horizontalmente, e assim como plantas atuais prensadas em um herbário, perdem sua tridimensionalidade, quando se trata de impressões e compressões. Em vida, os ramos de B. obesum teriam outro volume, pois poderiam crescer em diferentes direções, e mesmo presos aos fortes galhos, e compostos por folhas rijas, a gravidade poderia fazer com que alguns ramos ficassem pendentes ou levemente dobrados. Uma forma de ilustrar um possível volume de um vegetal extinto é utilizar vegetais atuais próximos filogenetica e morfologicamente ao fóssil estudado como referência para reconstrução. Fósseis de B. obesum sugerem que suas folhas eram muito semelhantes à de algumas espécies atuais da família Cupressaceae, 
assim, plantas desta família podem ser utilizadas como referência para reconstrução do volume e aspecto em vida de folhas e ramos de B. obesum, concluindo, deste modo, a coleta de informações necessárias a sua reconstrução (Fig. 13).

\section{Reconstrução do hábito de Brachyphylum obesum}

Os ramos de B. obesum indicam que este vegetal provavelmente teria um porte arbóreo, embora seja impossível estabelecer a silhueta e tamanho exato desta conífera baseando-se apenas em seus ramos. Alguns troncos fósseis isolados encontrados no Membro Romualdo são informalmente atribuídos a B. obesum, porém, até o momento, não há nenhum indício seguro que permita a inclusão de tais troncos nesta espécie. Assim, a reconstrução arbórea de B. obesum deve ser baseada em coníferas atuais que habitam em clima cálidos. O fator ambiental é muito importante, pois pode determinar a silhueta do vegetal. Espécies de coníferas que vivem em ambientes frios possuem geralmente um formato de cone, como os tradicionais pinheiros de natal. O formato permite melhor escoamento da neve, evitando que galhos se quebrem devido ao sobrepeso. Por outro lado, coníferas de ambientes mais quentes, quando adultas, apresentam silhueta irregular, com uma copa mais volumosa e assimétrica (Fig. 14), B. obesum foi uma conífera que viveu em um clima quente (Sucerquia \& Bernardes-de-Oliveira 2009) então é muito provável que tivesse uma silhueta irregular, como as atuais coníferas adaptadas ao ambiente quente.

A reconstrução arbórea de $B$. obesum inicia-se, então, com um esboço que lhe define uma possível silhueta, baseada em coníferas atuais de ambientes quentes (Fig. 15).

Uma vez definida a silhueta mais provável, a etapa seguinte resume-se em adequar o conjunto de rijos ramos de B. obesum ao esboço da silhueta, recriando desta forma seu aspecto arbóreo (Fig. 16).

\section{Reconstrução de Cor}

A parte externa do tronco da maioria dos vegetais de porte arbóreo, quando adultos, exibe cores quase sempre derivadas do marrom. As folhas, porém, podem ter maior diversidade de cor. As cores expostas nas folhas são produzidas pelos muitos pigmentos presentes nos vegetais. O pigmento que fornece a cor verde é produzido, maiormente pela clorofila, que também age como uma reserva

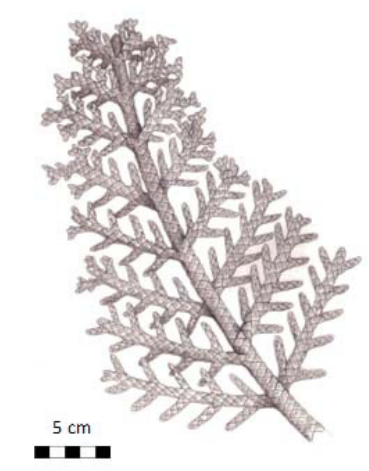

Figura 13. Reconstrução de ramos de Brachyphylum obesum. Ilustração de Ariel Milani Martine (Técnica 1)
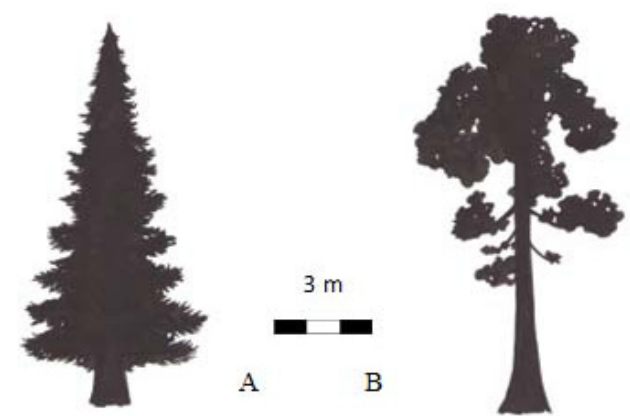

Figura 14. Comparação entre silhuetas de coníferas de ambiente frio (A) e ambiente quente (B). Ilustração de Ariel Milani Martine (Técnica 2)

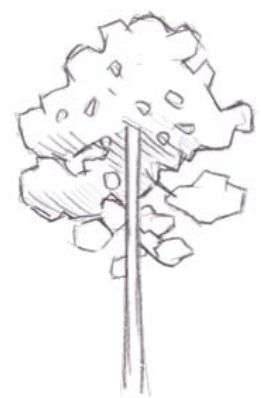

Figura 15. Esboço da possível silhueta de Brachyphylum obesum. Ilustração de Ariel Milani Martine (Técnica 1)

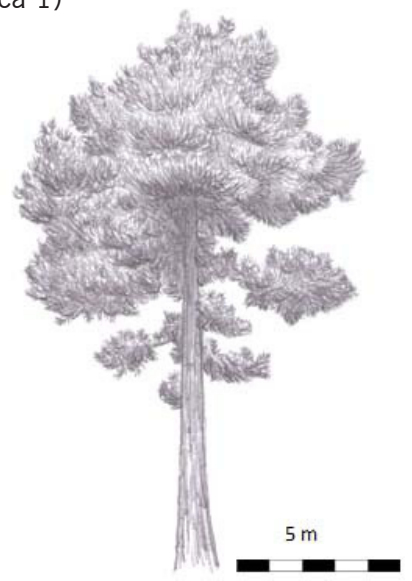

Figura 16. Reconstrução arbórea de Brachyphylum obesum. Ilustração de Ariel Milani Martine (Técnica 1) 
de energia solar. Os tons que vão do amarelo ao laranja intenso são produzidos pelos carotenóides, que absorvem luz com comprimentos de ondas diferentes dos da clorofila. Tons de vermelho vivo, violeta e azul são produzidos pelas antocianinas, sensíveis a fatores de PH do solo (Went 1983).

No decorrer do ano, condições atmosféricas induzem uma sucessão de pigmentos em muitas espécies de árvores de clima temperado, fazendo com que suas folhas mudem gradualmente de cor. Quando se encerra a fase de atividade das folhas, no início do outono, a produção de clorofila, que no verão e primavera pigmenta as folhas de verde, vai paulatinamente sendo substituída pelos carotenóides, que conferem uma tonalidade que vai do amarelo ao laranja avermelhado às folhas durante o outono até, finalmente, caírem durante o inverno. As folhas caducas são substituídas anualmente. Coníferas, de forma geral, possuem folhas perenes que mantêm os mesmos tons de verde o ano todo. Assim, pode-se concluir a reconstrução de B. obesum aplicando-lhes as mesmas tonalidades encontradas em coníferas atuais: tronco amarronzado e folhas que variam do verde musgo escuro ao verde oliva com brotos relativamente mais claros (Fig. 17).
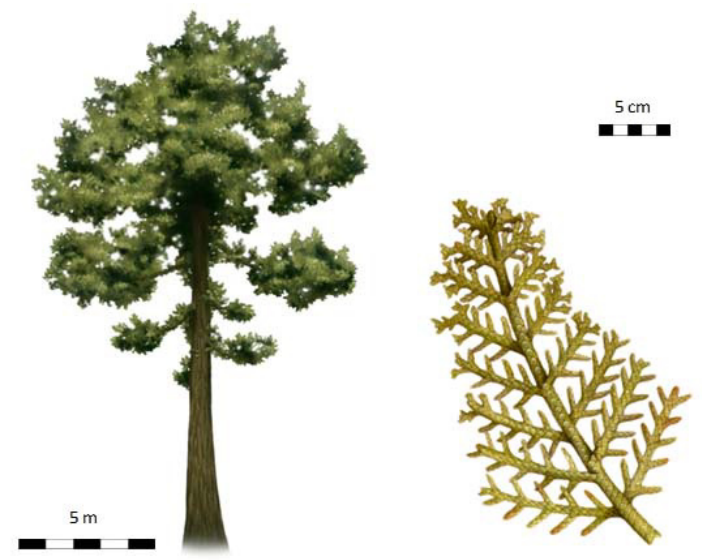

Figura 17. Reconstrução final de Brachyphylum obesum. Ilustração de Ariel Milani Martine (Técnica 5)

\section{Conclusões}

Reconstruções paleoartísticas executadas por intermédio de anatomia comparada podem reproduzir, atualmente, de forma muito aproximada, o aspecto em vida de um organismo fóssil. As reconstruções podem ser efetuadas em técnicas artísticas distintas, com acabamento monocromático ou colorido. Em técnicas monocromáticas, como grafite ou nanquim, a reconstrução final é mais conservadora, menos especulativa, mas também menos atraente para ser usada em divulgaçãos científica. A utilização de técnicas artísticas coloridas, como aquarela, tinta acrílica ou ilustração digital, apresentam o organismo fóssil reconstituído com sua possível coloração em vida. Uma vez que essa coloração não se encontra na grande maioria dos fósseis, a tarefa assume uma condição especulativa e empírica. Ainda assim, tais reconstruções são adequadas, pois além de levantar discussões sobre as possíveis relações paleoecológicas determinantes a coloração em vida do organismo, possuem também, maior atrativo visual.

\section{Referências}

Anderson P., Bright J., Gill P., Palmer C., Rayfield E. 2012. Models in palaeontological functional analysis. Biology Letters, 8:119-122.

Bakker R. 1988. The Dinosaur heresies. England, Penguin Books. 481 pp.

Bonaparte J.F. \& Powell J.E. 1980. A Continental assemblage of tetrapods from the Upper Cretaceous beds of El Brete, northwestern Argentina (Sauropoda-Coelurosauria-Carnosauria-Aves). Mém. Soc. Géol. France, n.s., 139:1928.

Borsuk-Bialynicka M. 1977. A new camarasaurid sauropod Opisthocoelicaudia skarzynkyi, gen n. sp. Nov. from the Upper Cretaceous of Mongolia. Palaeontologia Polonica 37:5-64.

Carvalho I.S Ed. 2000. Paleontologia. Rio de Janeiro: Editora Interciência. 628 p.

Chiasson R.B. 1962. Laboratory anatomy of the Alligator.WM. Dubuque: C. Brown Co. Publ., 56 pp.

Duarte L. 1985. Vegetais fósseis da Chapada do Araripe, Brasil. DNPM, Brasília, Coletân. Trab. Paleont., 27:585-617.

Heer O. 1881. Contributions à la flora fossile du Portugal. Communicações Trabalhos Servicio Geologia Portugal. 4:1-51.

Ihering H. 1913. Pleiodon priscus. In: Comissão Geográfica e Geológica. Exploração do Rio Grande e seus afluentes: São José dos Dourados, São Paulo. São Paulo: CGG/SP. 39p.

Kellner A.A.W.A., Azevedo S.A.K. 1999. A new sauropod dinosaur (titanosauria) from the late Cretaceous of Brazil. In: Tomida Y., Rich T.H. \& Vickers-Rich P. eds. 1999. Proceedings of the Second Gondwana Dinosaur Symposium. Tokyo: National Science Museum Monographs, p. 111-142.

Kunzmann L., Mohr B.A.R., Bernardes-de Oliveira M.E.C. 2004. Gymnosperms from the Lower Cretaceous Formation (Brazil). I. Araucariaceae and Lindleycladus (incertae sedis). Mitt. Mus. Nat. 
kd. berl., Geowiss. Reihe 7:155-174.

Lima F.J., Saraiva A.A.F., Sayão J.M. 2012. Revisão da paleoflora das Formações Missão Velha, Crato e Romualdo, Bacia do Araripe, nordeste do Brasil. Estudos Geológicos, 22(1):99-115.

Marinho T.S., Iori F.V. 2011. A large titanosaur (Dinosauria, sauropoda) osteoderm with possible bite marks from Ibirá, São Paulo State, Brazil. In: Carvalho I. S. Paleontologia: Cenários da vida. Vol 4. Rio de Janeiro, Editora Interciência. p. 367-377.

Mezzalira S. 1974. Contribuição ao conhecimento da Estratigrafia e paleontologia do arenito Baurú. São Paulo: Inst. Geoc. USP., 163 pp. (Tese Dout.).

Norman D. 1996. A Era dos Dinossauros Graficas Almudena, Madrid, 183 pp.

Novas F.E. 2009. The Age of Dinosaurs in South America. Bloomington, Indiana Univ. Press. 452p.

Paul G.S. Ed. 2000. The Scientific American Book of the best minds in paleontology creat a portrait of the prehistoric Era. New York: A Byron Preiss Book, $424 \mathrm{pp}$.

Paul G.S. 2010. The Princeton Field guide to Dinosaurs. New Jersey: Princeton Univ. Press. 320p.

Philippe M. 2009. Silhouette and palaeoecology of Mesozoic trees in Thailand. In: Buffetaut E., Cuny G., Le Loeuff J. \& Suteethorn V. eds. 2009. Late Paleozoic and Mesozoic Ecosystems in SE Asia. The Geological Society, Special Publications, 315:85-96.

Powell J.E. 1987. The Late Cretaceous fauna of Los
Alamitos, Patagonia, Argentina. Part VI. The titanosaurids. Rev. Mus. Argent. Cienc. Nat. Paleontol. 3:147-153.

Rudwick M.J.S. 1992. Scenes from Deep Time. Chicago: The Univ. of Chicago Press. 280p.

Santucci R.M., Arruda-Campos A.C.. 2011. A new sauropod (Macronaria, Titanosauria) from the Adamantina Formation, Bauru group, Upper Cretaceous of Brazil and phylogenetic relationship af Aeolosaurini. Zootaxa, 3085:1-33.

Sucerquia P.A., Bernardes-de-Oliveira M.E.C. 2009. Significado paleoclimático e paleoambiental de coníferas da família cheirolepidiaceae na flora da Formação Crato, Bacia do Araripe, Brasil. Paleontologia em Destaque, (63):25.

Upchurch P., Barret P.M., Dodson P. . 2004. Sauropoda. In: Weishampel D. B.,Dodson P. \& Osmólka H. eds. 2004. The Dinosauria. Los Angeles: Univ. California Press. p.259-322.

Wedel M.J. 2005. Postcranial in pneumaticity in sauropods and its implications for mass estimates. In: Rogers K.A.C. \& Wilson J.A. eds. 2005. The Sauropods Evolution and Paleobiology. London: Univ. California Press. p. 201-228.

Went F.W. 1983. As plantas. Rio de Janeiro: Livraria José Olympio Ed. 224p.

Xu X., Zhao Q., Norell M., Sullivan C., Hone D., Erickson G., Wang X., Han F., Guo Y.. 2009. A new feathered maniraptoran dinosaur fossil that fills a morphological gap in avian origin. Chinese Science bulletin, 52:430-435.

Resumo: Desde a metade do século XIX, paleontólogos usam desenhos e pinturas para reconstruir organismos extintos. Essas formas de reconstrução são chamadas hoje informalmente de reconstituições paleoartísticas. 0 espécime reconstruído por meio da ilustração científica transcende a literatura especializada, chegando ao conhecimento popular. Constitui, desse modo, importante ferramenta para a divulgação científica. Com base em anatomia comparada, o presente trabalho descreve, de forma pioneira, no Brasil, os conceitos e etapas dos processos de reconstituição paleoartística, usando como modelos três organismos fósseis brasileiros: um dinosauro saurópode (Aeolosaurus maximus), um molusco bivalve (Itaimbea priscus) e uma gimnosperma (Brachyphyllum obesum). A metodologia aplicada na reconstrução desses organismos pode ser também empregada para reconstrução de qualquer animal ou vegetal fóssil.

Palavras-Chave: Paleoarte, Reconstituições Paleontológicas 